\title{
Anti-inflammatory Nanoparticle for Prevention of Atherosclerotic Vascular Diseases
}

\author{
Jun-ichiro Koga ${ }^{1,2}$, Tetsuya Matoba² and Kensuke Egashira ${ }^{1,2}$
}

${ }^{1}$ The Department of Cardiovascular Research, Development, and Translational Medicine, Center for Disruptive Cardiovascular Medicine, Kyushu University, Fukuoka, Japan

${ }^{2}$ The Department of Cardiovascular Medicine, Graduate School of Medical Sciences, Kyushu University, Fukuoka, Japan

\begin{abstract}
Recent technical innovation has enabled chemical modifications of small materials and various kinds of nanoparticles have been created. In clinical settings, nanoparticle-mediated drug delivery systems have been used in the field of cancer care to deliver therapeutic agents specifically to cancer tissues and to enhance the efficacy of drugs by gradually releasing their contents. In addition, nanotechnology has enabled the visualization of various molecular processes by targeting proteinases or inflammation. Nanoparticles that consist of poly (lactic-co-glycolic) acid (PLGA) deliver therapeutic agents to monocytes/macrophages and function as anti-inflammatory nanoparticles in combination with statins, angiotensin receptor antagonists, or agonists of peroxisome proliferator-activated receptor- $y$ $(\operatorname{PPAR} \gamma)$. PLGA nanoparticle-mediated delivery of pitavastatin has been shown to prevent inflammation and ameliorated features associated with plaque ruptures in hyperlipidemic mice. PLGA nanoparticles were also delivered to tissues with increased vascular permeability and nanoparticles incorporating pitavastatin, injected intramuscularly, were retained in ischemic tissues and induced therapeutic arteriogenesis. This resulted in attenuation of hind limb ischemia. Ex vivo treatment of vein grafts with imatinib nanoparticles before graft implantation has been demonstrated to inhibit lesion development. These results suggest that nanoparticle-mediated drug delivery system can be a promising strategy as a next generation therapy for atherosclerotic vascular diseases.
\end{abstract}

J Atheroscler Thromb, 2016; 23: 757-765.

Key words: Nanoparticle, Inflammation, Statin, Atherosclerosis

\section{Recent Advances in Drug Delivery System}

Atherosclerotic vascular diseases, including acute myocardial infarction and stroke, are life-threatening diseases. Monocyte/macrophage-mediated inflammation is one of the central mechanisms of plaque formation and subsequent atherothrombotic complications ${ }^{1,2)}$. Activated macrophages also contribute to the pathogenesis of various metabolic disorders including fatty liver disease and obesity ${ }^{3)}$. The incidence of acute

Address for correspondence: Jun-ichiro Koga, The Department of Cardiovascular Research, Development, and Translational Medicine, Center for Disruptive Cardiovascular Medicine, Kyushu University; 3-3-1, Maidashi, Higashi-ku, Fukuoka, Japan 812-8582

E-mail: j-koga@cardiol.med.kyushu-u.ac.jp

Received: January 29, 2016

Accepted for publication: March 8, 2016 myocardial infarction has been increasing in Japan according to lifestyle changes such as Western style diets and physical inactivity ${ }^{4,5)}$. Current therapies, including intensive cholesterol lowering by HMGCoA (hydroxymethylglutaryl-CoA) reductase inhibitor (statin), are not sufficient to prevent future cardiovascular events. However, statin has been shown to have several favorable effects including antioxidant effect or anti-inflammatory effects ${ }^{6,7)}$. As shown in the JUPITER trial, intensive cholesterol lowering therapy in patients with hs-CRP $\geqq 2 \mathrm{mg} / \mathrm{L}$ decreased $44 \%$ of the major cardiovascular events, but half of the cardiovascular events were not prevented ${ }^{8)}$. Therefore, novel therapeutics targeting unrecognized residual risk factors other than currently known risk factors, i.e., LDL cholesterol, hypertension, diabetes etc., are desired. On the other hand, technical innovations in the field of drug delivery system have made it possible to deliver 
Table 1. Nanoparticles used for research of atherosclerosis

\begin{tabular}{lccccc}
\hline & Micelle & Liposome & Polymeric nanosphere & Dendrimer & Carbon nanotube \\
\hline Feature & $\begin{array}{c}\text { Self-assembled } \\
\text { monolayer }\end{array}$ & lipid bilayer & Bioabsorbable & $\begin{array}{c}\text { Monodisperse, } \\
\text { repetitively branched } \\
\text { molecules }\end{array}$ & $\begin{array}{c}\text { Allotropes of carbon, } \\
\text { Carcinogenicity? }\end{array}$ \\
\hline Particle size & $1-100 \mathrm{~nm}$ & $40-1,000 \mathrm{~nm}$ & $20-1,000 \mathrm{~nm}$ & $3-20 \mathrm{~nm}$ & $1 \times 20-40 \mathrm{~nm}$ \\
\hline Advantage & $\begin{array}{c}\text { Easily synthesized, } \\
\text { Stable in the body }\end{array}$ & $\begin{array}{c}\text { Safely metabolized, } \\
\text { interaction with } \\
\text { membrane }\end{array}$ & $\begin{array}{c}\text { Particle size is adjustable, } \\
\text { Excellent storage } \\
\text { stability }\end{array}$ & $\begin{array}{c}\text { Delivery of } \\
\text { hydrophobic agents }\end{array}$ & $\begin{array}{c}\text { Chemical modification, } \\
\text { photo dynamic therapy }\end{array}$ \\
\hline Reference & $53-55$ & 36,37 & 45,49 & 56,57 & 58,59 \\
\hline
\end{tabular}

various drugs to specific organs or cells. This approach could maximize the drug efficacies while reducing systemic undesired effects. In this review, we summarize the current progress of nanotechnology in atherosclerotic vascular diseases including our own results.

\section{Nanotechnology-Based Drug Delivery System as a Therapeutic Modality}

In the past decade, various nanomaterials were created and some of them have been already used in clinical settings. Examples of nanomaterials include nanotubes ${ }^{9,10)}$ nanorod ${ }^{11)}$ or dendrimers ${ }^{12)}$. The most popular one is the nanosphere such as a micelle, liposome or, polymer nanoparticle. Some nanoparticles target specific types of cells through modifying the surface of the particles (antibodies ${ }^{13,14)}$, protein $\left.{ }^{15}\right)$. Some nanoparticles are sensitive to specific $\mathrm{pH}$ or specific temperature and release encapsulated agents specifically in the targeted tissues/cells ${ }^{16-19)}$. These intelligent nano-sized delivery systems have excellent targeting efficacy and can minimize undesired adverse effects in non-targeting sites. Many materials, including high molecular weight polymers, lipids, metals (gold etc.) and carbon, are used to formulate various types of nanomaterials (Table 1) ${ }^{20)}$. In general, nanomaterialbased drug delivery systems have the following advantages: 1) incorporation of high payload of drugs; 2) improved pharmacokinetics and bioavailability; and 3) surface functionalization ${ }^{21}$. In vivo kinetics of these nanomaterials predominantly depends on the particle size. Many spherical nanoparticles with diameters of $10-300 \mathrm{~nm}$ have prolonged retention time in circulating blood by escaping elimination at the glomeruli in the kidneys. Such nanoparticles also escape from extravasation depending on the endothelial barrier. Relatively large nanoparticles with more than 60-80 $\mathrm{nm}$ diameters escape from extravasation in capillaries of normal tissues that have fenestrae between 60-80 $\mathrm{nm}$. In tumor tissues or at the site of inflammation, the integrity of these endothelial layers is impaired and the nanoparticles can extravasate to the extravascular space through the enlarged interspace between endothelial cells. In tumor tissues, immature lymphatic vessels retard elimination of nanoparticles. These effects are known as enhanced permeability and retention effects $^{22,23)}$. Surface modification with polyethylene glycol (PEG) prevents entrapment of nanoparticles by the reticuloendothelial system due to its hydrophilic property. Therefore, these nanoparticles are called stealth nanoparticles ${ }^{24,25)}$.

\section{Nanoparticles as a Research Tool for Atherosclerosis}

Clinical applications of nanoparticles are advanced in the field of diagnostic medicine. For example, magnetic nanoparticles with iron cores are available in MRI for macrophage imaging ${ }^{26}$. These so-called superparamagnetic iron oxide (SPIO) nanoparticles are used as a negative contrast agent in MRI. The iron core is modified with hydrophilic polymers including dextran, carboxymethylated dextran, polyvinyl alcohol, starches, chitosan, polymethyl methacrylate, PEG, poly (lactic-co-glycolic) acid (PLGA), polyvinylpyrrolidone, and polyacrylic acid ${ }^{27)}$. These particles have been tested in patients to evaluate inflammation, plaque vulnerability, and therapeutic effects of lipid lowering drugs, especially in the carotid arteries of patients ${ }^{26,28,29)}$.

Adhesion molecules are also targets of molecular imaging. Under hyperlipidemic conditions, expressions of adhesion molecules, including vascular cell adhesion molecule-1 (VCAM-1) and intracellular adhesion molecule-1 (ICAM-1), increase in endothelial cells and promote attachment of monocytes recruited by monocyte chemoattractant protein-1 (MCP-1) ${ }^{30-32)}$. Therefore, these molecules could be a target for monitoring the inflammatory milieu of athero-prone vasculatures. 
Weissleder et al. successfully visualized VCAM-1 in atherosclerotic plaques of ApoE-deficient mice by using MRI and cross-linked iron oxide nanoparticle modified with VCAM-1 ligand ${ }^{33)}$. In addition, Samuel et al. reported a nanoprobe for MRI that has gadolinium core and modified with perfluorocarbon and anti$\alpha \mathrm{v} \beta 3$-integlin antibody. This particle was able to visualize early atherosclerotic changes in the carotid artery of hyperlipidemic rabbits ${ }^{34)}$.

In the preclinical stage, nanoparticles have been used as a research tool to visualize various molecular processes in atherosclerotic model animals. Nano-sized probes with near infrared fluorescence (NIRF) are often used. NIRF probes have excitation/emission wavelengths between 600-900 $\mathrm{nm}$ and the absorbance of fluorescence by hemoglobin or water is negligible in this range of wavelength. These probes are designed to have a protease-specific quenched substrate, which is inserted between the fluorescence and carrier vehicle. Once the substrate is cleaved by specific proteinases (matrix metalloproteinase (MMP), cathepsin etc.), the probe elaborates NIRF signals (activated state). These probes are used in molecular imaging to evaluate protease activities and the therapeutic efficacy of various drugs on these proteases ${ }^{27,35}$. Nanoparticles incorporating siRNA could be also as an excellent research tool. By using this kind of nanoparticle, two or more genes are knocked down simultaneously. In combination with cell type-specific nanoparticles, specific genes can be knocked down in live animals without timeconsuming and costly procedures (i.e., establishment of genetically-altered mice) ${ }^{36,37)}$.

\section{PLGA Nanoparticles for the Treatment of Cardiovascular Diseases}

We have developed a drug delivery system based on PLGA nanoparticles (PLGA-NPs) ${ }^{38-40)}$. PLGA-NPs were prepared by solvent emulsion diffusion method and the mean diameter of particles was $200 \mathrm{~nm}$ $(\text { Fig. 1A })^{41)}$. In the bloodstream, PLGA-NPs of this size can escape from clearances in the kidneys and reticuloendothelial system, which prolongs the blood retention time. This results in effective drug delivery to the target site with increased vascular permeability ${ }^{42,43)}$. In addition, inflammatory cells, especially monocytes/macrophages, take up these sized particles, suggesting the potential of PLGA-NPs as a platform for novel anti-inflammatory therapies. PLGA-NPs also have the following advantages as a drug carrier: 1) PLGA has been used in the clinical settings for over forty years ${ }^{44)}$ and there are limited safety concerns; and 2) PLGA can encapsulate both hydrophobic and hydrophilic agents including chemicals and nucleotides. After intravenous injection, PLGA-NPs are taken up by circulating monocytes within 30 minutes. Parts of nanoparticles are also delivered to the lymphocytes and neutrophils. In atherosclerotic plaques, PLGA nanoparticles are predominantly delivered to plaque macrophages and little, if any, were delivered to the lymphocytes and neutrophils ${ }^{45)}$.

We have demonstrated the efficacy of this drug delivery system in various animal models of atherosclerotic vascular diseases. By coating stents with PLGA-NPs containing anti-proliferative or anti-inflammatory drugs, these stents can be used to prevent restenosis after vascular intervention. We have reported a novel method to coat metal stents electrically and demonstrated the in vivo efficacy of stents coated with nanoparticles incorporated with imatinib mesylate, a tyrosine kinase inhibitor of PDGF receptor (ImatinibNPs), or Pitava-NPs ${ }^{46,47)}$. After implantation of these stents in injured vasculatures, drugs coated on the stents surface are released and delivered to the surrounding vascular walls. This method has an advantage in that sufficient amount of drugs can be delivered locally to the injured vessels without apparent systemic adverse effects.

We recently reported that Pitava-NPs decreased inflammatory Ly-6C high monocytes in peripheral blood (Fig. 1B). In addition, Pitava-NPs decreased buried fibrous caps, a surrogate marker of healed plaque ruptures, in the brachiocephalic arteries of mice (Fig. 2) ${ }^{45)}$. Equivalent doses of pitavastatin did not show any apparent effects, suggesting that nanoparticle-mediated efficient drug delivery to inflammatory monocytes retards atherosclerotic lesion formation, plaque destabilization, and inhibits plaque ruptures. Furthermore, Pitava-NPs inhibited the formation of abdominal aortic aneurysms in hyperlipidemic ApoEdeficient mice (unpublished data). We recently reported data about PLGA-NPs incorporating pioglitazone (Pio-NP). In hyperlipidemic ApoE-deficient mice with angiontensin II infusion, Pio-NPs decreased the buried fibrous caps in mouse brachiocephalic arteries. Pio-NPs also decreased Ly-6C ${ }^{\text {high }}$ monocytes in the peripheral blood and MMP activities, which were evaluated by molecular imaging with NIRF probes (Fig. 3) ${ }^{48)}$. These results suggest that the anti-inflammatory property of Pitava-NPs and Pio-NPs induced porality shift from inflammatory ' $\mathrm{M} 1$ ' macrophages to less inflammatory ' $\mathrm{M} 2$ ' macrophages.

The PLGA-NP mediated drug delivery system is effective in other vascular diseases. We have reported that the nanoparticle-mediated delivery of pitavastatin promotes therapeutic angiogenesis in hind limb isch- 


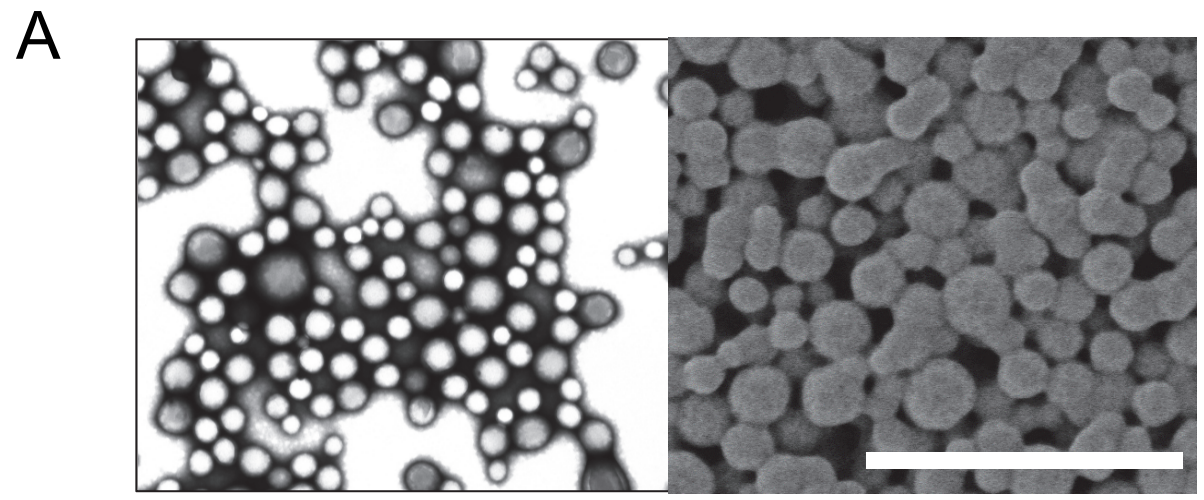

B
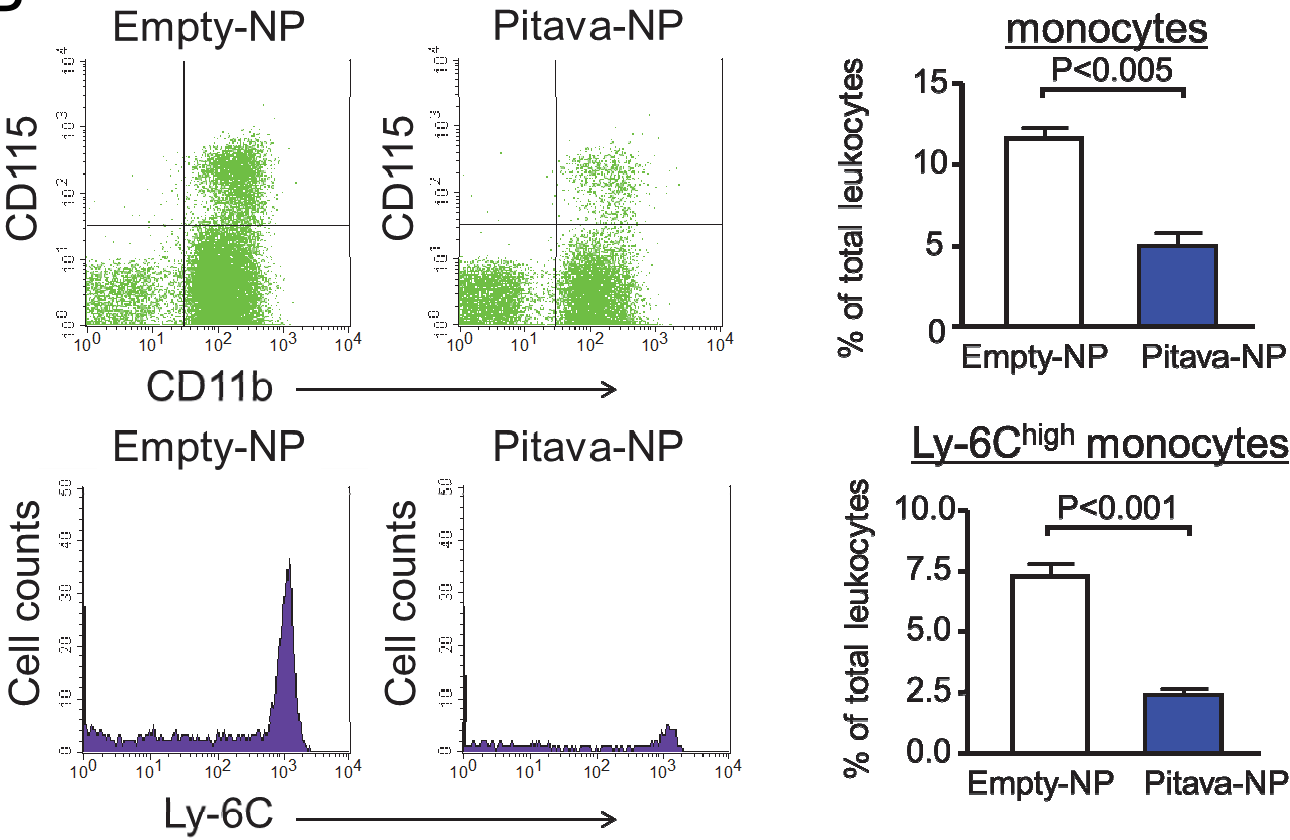

Fig. 1. PLGA nanoparticles and their in vivo targeting of circulating inflammatory monocytes.

(A) PLGA nanoparticles prepared by the emulsion solvent diffusion method. Images were taken by the transmission electron microscope (left) and scanning electron microscope (right). Scale bar indicates $1 \mu \mathrm{m}$. (B) Flow cytometry of circulating leukocytes. CD $11 \mathrm{~b}^{+} \mathrm{CD} 115^{+}$cells are quantified as circulating monocytes (upper panels). Inflammatory monocytes determined by Ly-6C expression were evaluated (lower panels). Right graphs show quantitative data. $\mathrm{N}=3-4$.

emia $^{39,49,50)}$. This therapeutic angiogenesis may be a potential novel therapy for patients with peripheral arterial diseases because there are no available medical therapies other than surgical revascularization. We are currently conducting a Phase I/II clinical study to confirm the safety and efficacy of Pitava-NPs on critical limb ischemia in patients without other therapeutic options.

The occlusion of vein grafts is also an often experienced complication after coronary arterial bypass grafting or revasculalization of peripheral arterial diseases. The number of patients with critical limb ischemia increases each year and the number of patients undergoing bypass surgeries with vein grafts is also increasing. Occlusions of arterial-venous shunt in patients with end-stage renal failure can be considered a kind of vein graft disease. In these patients, intimal hyperplasia and subsequent obstruction of the graft causes life-threatening situations and a loss in the quality of life. Macrophage activation and smooth muscle 
A

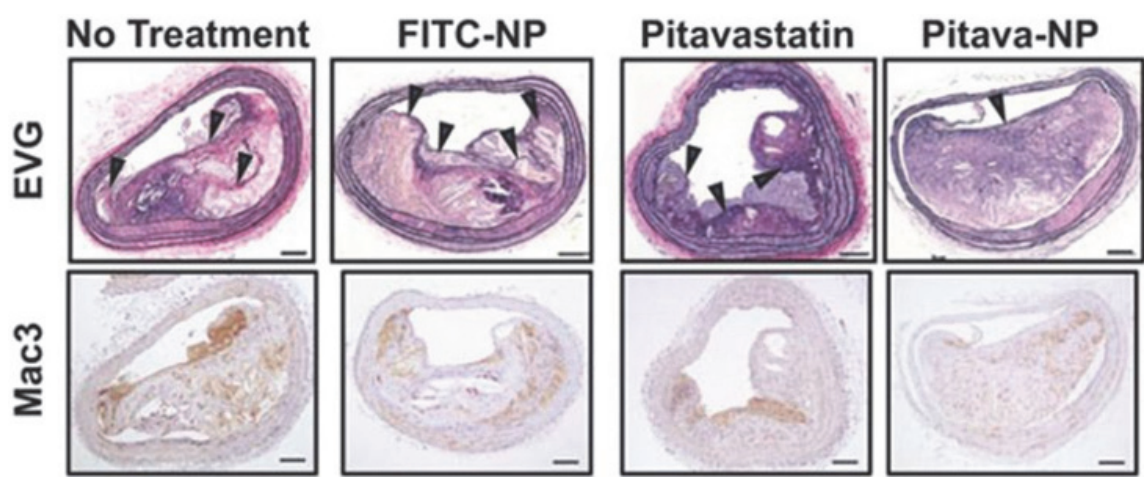

\section{B Disrupted/buried Fibrous Cap Fibrous caps Thickness}

\section{Mac3}
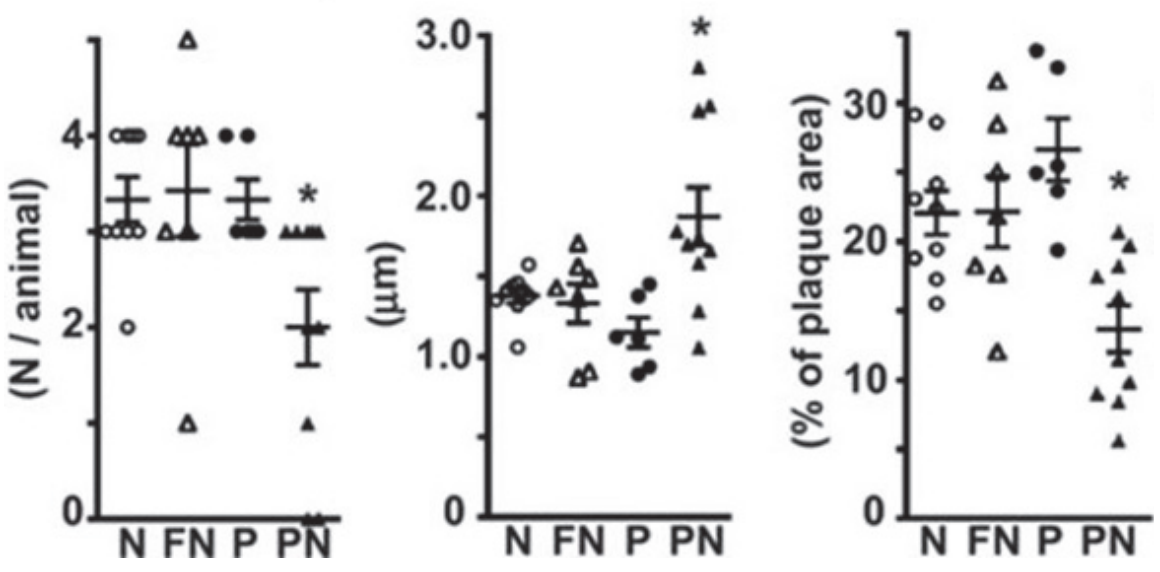

Fig. 2. PLGA nanoparticles incorporating pitavastatin decrease buried fibrous caps in the brachiocephalic artery.

(A) ApoE-deficient mice (16 weeks) were fed a high-fat diet for 4 weeks and then infused with angiotensin II for an additional 4 weeks. PLGA nanoparticles incorporating $0.4 \mathrm{mg} / \mathrm{kg}$ pitavastatin were injected into the tail vein once a week after starting angiotensin $\amalg$. The buried fibrous cap was identified after staining with elastica van Gieson (EVG) staining (above). Macrophage accumulation was determined as Mac3 positive area (below). NP; nanoparticle. Scale bar indicates $100 \mu \mathrm{m}$. (B) Quantitative analyses of buried fibrous caps, the thickness of fibrous caps, and macrophage accumulation. ${ }^{*} P<0.05$ vs. no-treatment group. N; negative control, FN; NPs containing FITC (fluorescein isothiocyanate), P; pitavastatin, PN; NPs containing pitavastatin. (Modified and cited from reference 45)

proliferation promote the pathobiology of vein graft lesion development ${ }^{36)}$. Therefore, we have tested the effect of nanoparticles encapsulating tyrosine kinase inhibitor of PDGF (platelet-derived growth facor) receptor (Imatinib-NPs). Ex vivo treatments of vein grafts before implantation decreased intimal thickness ${ }^{51)}$. In this case, smooth muscle cells took up the nanoparticles after incubating the graft with PLGANPs.

\section{PLGA Nanoparticles for the Treatments of Ischemia-Reperfusion Injury}

Acute myocardial infarction is a complication of advanced atherosclerosis. Percutaneous coronary intervention in acute phase decreases the infarct size, but reperfusion injury limits its therapeutic efficacy. After reperfusion of the coronary artery, monocytes/macrophages accumulate to the infarcted area. In acute phase, Ly-6C high inflammatory monocytes infiltrate into the infarcted area and differentiate into inflammatory ' $\mathrm{M} 1$ ' macrophages ${ }^{52)}$. These macrophages release inflamma- 
A

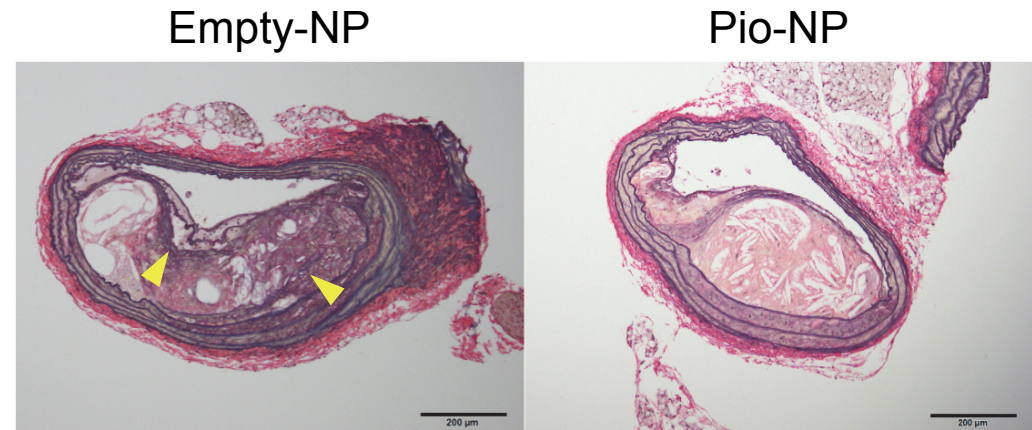

B

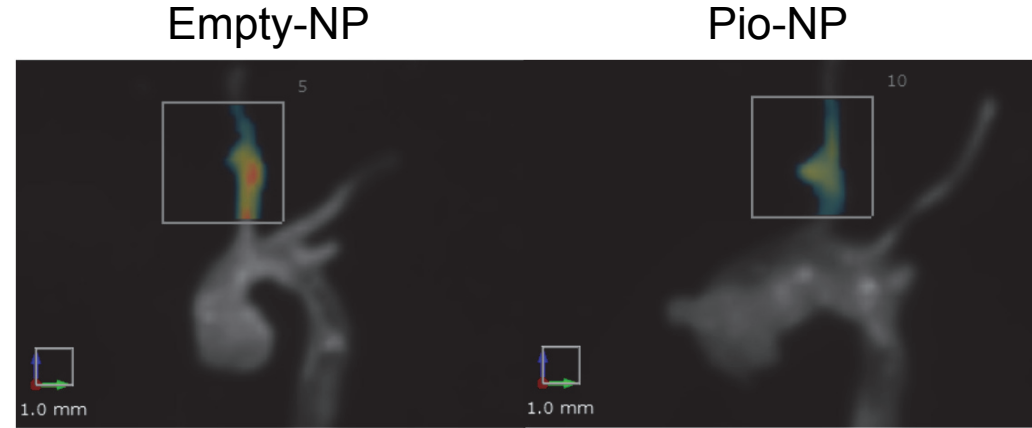

Fig.3. Nanoparticle-mediated delivery of pioglitazone decreases buried fibrous caps and inhibits MMP activities.

(A) ApoE-deficient mice (16 weeks) were fed a high-fat diet for 4 weeks and then angiotensin II was administered for an additional 4 weeks. PLGA nanoparticles incorporating $7 \mathrm{mg} / \mathrm{kg}$ pitavastatin were injected into the tail vein once a week. The buried fibrous cap was identified after staining with elastica van Gieson (EVG) staining (above). The arrowheads indicate buried fibrous caps. (B) MMP activities were evaluated by a NIRF probe (i.e., MMPsense750). Activated MMP cleaved the quenched site of MMPsense and the emitted NIRF signal was detected in the brachiocephalic arteries. In contrast, Pio-NP inhibited MMP activities when compared to empty-NPs. $\mathrm{N}=5-6$. (Modified and cited from reference 48)

tory cytokines and various proteinases which promote apoptotic/necrotic cell death of cardiomyocytes. Subsequently, less inflammatory 'M2' macrophages accumulate and promote infarct healing. In vivo silencing of CCR2 in monocytes/macrophages by siRNA, which are incorporated in lipid nanoparticles, decreases macrophage accumulation and reduces infarcted area in a mouse model of ischemia reperfusion injury in the heart ${ }^{37)}$. Therefore, PLGA-NPs with anti-inflammatory drugs could be a novel therapy for ischemia reperfusion injury. In rat ischemia/reperfusion injury in the heart, Pitava-NPs decreased inflammation and cardiomyocyte death through the PI3K/Akt pathway ${ }^{38)}$. In addition, nanoparticles incorporating the angiotensin receptor blocker irbesartan decreased the accumulation of inflammatory monocytes and reduced the infarct size (unpublished data).

\section{Conclusion}

The recent progress of nanotechnology has resulted in the development of diagnostic modalities and therapeutic agents. In the cardiovascular field, some nanoparticles are undergoing clinical trials. For example, Alnylam presented the initial clinical data of nanoparticles containing PCSK9 (proprotein convertase subtilisin/kexin type 9) siRNA. Subcutaneous injection of this nanoparticle decreased LDL cholesterol up to $64 \%$, even in patients with prior statin usage.

Our data indicate that anti-inflammatory PLGANPs could be a promising strategy to treat various cardiovascular diseases. We are currently conducting a clinical trial to test the efficacy of nanoparticle-mediated delivery of pitavastatin in patients with critical limb ischemia. Dynamic collaborative research is necessary to promote the rapid development and clinical 
application of nanoparticle-based therapeutics.

\section{Acknowledgement}

This work was supported by Grants-in-Aid for Scientific Research from the Ministry of Education, Science, and Culture, Tokyo, Japan (15K19384 to JK, 25461135 to TM, 22390160 and 25293185 to KE), the Translational Research Network Program from the Ministry of Education, Science, and Culture, Tokyo, Japan (to KE) and Health Science Research Grants (Research on Translational Research and Nanomedicine, Research on Nanomedicine and on Intractable Diseases) from the Ministry of Health, Labor, and Welfare, Tokyo, Japan (to KE).

\section{Conflict of Interest}

Dr. Egashira is the inventor of an issued patent on part of the results reported in the present study (Pharmaceutical composition containing statin-encapsulated nanoparticle, WO 2008/026702). Applicants for this patent include Kyushu University (http://imaq. kyushu-u.ac.jp/), KOWA Inc (http://www.kowa.co.jp), and Sentan Medical Inc (http://sentaniryou.co.jp). Sentan Medical Inc is a drug discovery venture company from Kyushu University. Dr. Egashira is a founder of Sentan Medical Inc, possessing stocks, serves as one of Directors of the company, and reports personal fees from the company outside the submitted work. The intellectual property division of Kyushu University is reviewing that Sentan Medical Inc did not play a direct role in the study design, data collection and analysis, decision to publish, or preparation of the manuscript in Dr. Egashira's Laboratory.

\section{References}

1) Libby P, Tabas I, Fredman G, Fisher EA. Inflammation and its resolution as determinants of acute coronary syndromes. Circ Res. 2014; 114: 1867-1879

2) Libby P. Inflammation in atherosclerosis. Nature. 2002; 420: 868-874

3) Komohara Y, Fujiwara Y, Ohnishi K, Shiraishi D, Takeya M. Contribution of macrophage polarization to metabolic diseases. J Atheroscler Thromb. 2016; 23: 10-17

4) Kitamura A, Sato S, Kiyama M, Imano H, Iso H, Okada T, Ohira T, Tanigawa T, Yamagishi K, Nakamura M, Konishi M, Shimamoto T, Iida M, Komachi Y. Trends in the incidence of coronary heart disease and stroke and their risk factors in japan, 1964 to 2003: The akita-osaka study. J Am Coll Cardiol. 2008; 52: 71-79

5) Rumana N, Kita Y, Turin TC, Murakami Y, Sugihara H, Morita Y, Tomioka N, Okayama A, Nakamura Y, Abbott $\mathrm{RD}$, Ueshima $\mathrm{H}$. Trend of increase in the incidence of acute myocardial infarction in a japanese population: Takashima ami registry, 1990-2001. Am J Epidemiol. 2008; 167: 1358-1364

6) Lim S, Barter P. Antioxidant effects of statins in the management of cardiometabolic disorders. J Atheroscler Thromb. 2014; 21: 997-1010

7) Nakagomi A, Shibui T, Kohashi K, Kosugi M, Kusama Y, Atarashi H, Shimizu W. Differential effects of atorvastatin and pitavastatin on inflammation, insulin resistance, and the carotid intima-media thickness in patients with dyslipidemia. J Atheroscler Thromb. 2015; 22: 1158-1171

8) Ridker PM, Danielson E, Fonseca FA, Genest J, Gotto AM, Jr., Kastelein JJ, Koenig W, Libby P, Lorenzatti AJ, MacFadyen JG, Nordestgaard BG, Shepherd J, Willerson JT, Glynn RJ, Group JS. Rosuvastatin to prevent vascular events in men and women with elevated c-reactive protein. N Engl J Med. 2008; 359: 2195-2207

9) Klingeler R, Hampel S, Buchner B. Carbon nanotube based biomedical agents for heating, temperature sensoring and drug delivery. Int J Hyperthermia. 2008; 24: 496505

10) Wu J, Paudel KS, Strasinger C, Hammell D, Stinchcomb AL, Hinds BJ. Programmable transdermal drug delivery of nicotine using carbon nanotube membranes. Proc Natl Acad Sci U S A. 2010; 107: 11698-11702

11) Ankri R, Melzer S, Tarnok A, Fixler D. Detection of gold nanorods uptake by macrophages using scattering analyses combined with diffusion reflection measurements as a potential tool for in vivo atherosclerosis tracking. Int J Nanomedicine. 2015; 10: 4437-4446

12) Bosnjakovic A, Mishra MK, Ren W, Kurtoglu YE, Shi T, Fan D, Kannan RM. Poly(amidoamine) dendrimer-erythromycin conjugates for drug delivery to macrophages involved in periprosthetic inflammation. Nanomedicine. 2011; 7: 284-294

13) Xiao B, Laroui H, Viennois E, Ayyadurai S, Charania MA, Zhang Y, Zhang Z, Baker MT, Zhang B, Gewirtz AT, Merlin D. Nanoparticles with surface antibody against cd98 and carrying cd98 small interfering rna reduce colitis in mice. Gastroenterology. 2014; 146: 1289-1300 e1281-1219

14) Kocbek P, Obermajer N, Cegnar M, Kos J, Kristl J. Targeting cancer cells using plga nanoparticles surface modified with monoclonal antibody. J Control Release. 2007; 120: $18-26$

15) Esfandyari-Manesh M, Mostafavi SH, Majidi RF, Koopaei MN, Ravari NS, Amini M, Darvishi B, Ostad SN, Atyabi F, Dinarvand R. Improved anticancer delivery of paclitaxel by albumin surface modification of plga nanoparticles. Daru. 2015; 23: 28

16) Zhang P, Song X, Tong W, Gao C. Nanoparticle/polymer assembled microcapsules with ph sensing property. Macromol Biosci. 2014; 14: 1495-1504

17) Song X, Li H, Tong W, Gao C. Fabrication of triplelabeled polyelectrolyte microcapsules for localized ratiometric ph sensing. J Colloid Interface Sci. 2014; 416: 252-257

18) Lapresta-Fernandez A, Doussineau T, Dutz S, Steiniger F Moro AJ, Mohr GJ. Magnetic and fluorescent core-shell nanoparticles for ratiometric ph sensing. Nanotechnology. 
2011; 22: 415501

19) Kono K, Takashima M, Yuba E, Harada A, Hiramatsu Y, Kitagawa H, Otani T, Maruyama K, Aoshima S. Multifunctional liposomes having target specificity, temperature-triggered release, and near-infrared fluorescence imaging for tumor-specific chemotherapy. J Control Release. 2015; 216: 69-77

20) Matoba T, Egashira K. Nanoparticle-mediated drug delivery system for cardiovascular disease. Int Heart J. 2014; 55: 281-286

21) Lameijer MA, Tang J, Nahrendorf M, Beelen RH, Mulder WJ. Monocytes and macrophages as nanomedicinal targets for improved diagnosis and treatment of disease. Expert Rev Mol Diagn. 2013; 13: 567-580

22) Tanaka T, Shiramoto S, Miyashita M, Fujishima $Y$, Kaneo Y. Tumor targeting based on the effect of enhanced permeability and retention (epr) and the mechanism of receptor-mediated endocytosis (rme). Int J Pharm. 2004; 277: 39-61

23) Asai T. Nanoparticle-mediated delivery of anticancer agents to tumor angiogenic vessels. Biol Pharm Bull. 2012; 35: 1855-1861

24) Yang A, Liu W, Li Z, Jiang L, Xu H, Yang X. Influence of polyethyleneglycol modification on phagocytic uptake of polymeric nanoparticles mediated by immunoglobulin $g$ and complement activation. J Nanosci Nanotechnol. 2010; 10: 622-628

25) Hatakeyama $H$, Akita $H$, Harashima $H$. The polyethyleneglycol dilemma: Advantage and disadvantage of pegylation of liposomes for systemic genes and nucleic acids delivery to tumors. Biol Pharm Bull. 2013; 36: 892899

26) Metz S, Beer AJ, Settles M, Pelisek J, Botnar RM, Rummeny EJ, Heider P. Characterization of carotid artery plaques with uspio-enhanced mri: Assessment of inflammation and vascularity as in vivo imaging biomarkers for plaque vulnerability. Int J Cardiovasc Imaging. 2011; 27: 901-912

27) Weissleder R, Nahrendorf M, Pittet MJ. Imaging macrophages with nanoparticles. Nat Mater. 2014; 13: 125-138

28) Trivedi RA, Mallawarachi C, JM UK-I, Graves MJ, Horsley J, Goddard MJ, Brown A, Wang L, Kirkpatrick PJ, Brown J, Gillard JH. Identifying inflamed carotid plaques using in vivo uspio-enhanced $\mathrm{mr}$ imaging to label plaque macrophages. Arterioscler Thromb Vasc Biol. 2006; 26: 1601-1606

29) Chan JM, Monaco C, Wylezinska-Arridge M, Tremoleda JL, Gibbs RG. Imaging of the vulnerable carotid plaque: Biological targeting of inflammation in atherosclerosis using iron oxide particles and mri. Eur J Vasc Endovasc Surg. 2014; 47: 462-469

30) Nakashima Y, Raines EW, Plump AS, Breslow JL, Ross R. Upregulation of vcam-1 and icam-1 at atherosclerosisprone sites on the endothelium in the apoe-deficient mouse. Arterioscler Thromb Vasc Biol. 1998; 18: 842851

31) Kowala MC, Recce R, Beyer S, Gu C, Valentine M. Characterization of atherosclerosis in ldl receptor knockout mice: Macrophage accumulation correlates with rapid and sustained expression of aortic mcp-1/je. Atherosclerosis.
2000; 149: 323-330

32) Kitamoto S, Egashira K. Gene therapy targeting monocyte chemoattractant protein-1 for vascular disease. J Atheroscler Thromb. 2002; 9: 261-265

33) Nahrendorf M, Jaffer FA, Kelly KA, Sosnovik DE, Aikawa E, Libby P, Weissleder R. Noninvasive vascular cell adhesion molecule-1 imaging identifies inflammatory activation of cells in atherosclerosis. Circulation. 2006; 114: 1504-1511

34) Winter PM, Morawski AM, Caruthers SD, Fuhrhop RW, Zhang H, Williams TA, Allen JS, Lacy EK, Robertson JD, Lanza GM, Wickline SA. Molecular imaging of angiogenesis in early-stage atherosclerosis with alpha(v) beta3-integrin-targeted nanoparticles. Circulation. 2003; 108: $2270-2274$

35) Quillard T, Tesmenitsky Y, Croce K, Travers R, Shvartz E, Koskinas KC, Sukhova GK, Aikawa E, Aikawa M, Libby P. Selective inhibition of matrix metalloproteinase-13 increases collagen content of established mouse atherosclerosis. Arterioscler Thromb Vasc Biol. 2011; 31: 24642472

36) Koga JI, Nakano T, Dahlman JE, Figueiredo JL, Zhang H, Decano J, Khan OF, Niida T, Iwata H, Aster JC, Yagita H, Anderson DG, Ozaki CK, Aikawa M. Macrophage notch ligand delta-like 4 promotes vein graft lesion development: Implications for the treatment of vein graft failure. Arterioscler Thromb Vasc Biol. 2015:

37) Leuschner F, Dutta P, Gorbatov R, Novobrantseva TI, Donahoe JS, Courties G, Lee KM, Kim JI, Markmann JF, Marinelli B, Panizzi P, Lee WW, Iwamoto Y, Milstein S, Epstein-Barash H, Cantley W, Wong J, Cortez-Retamozo V, Newton A, Love K, Libby P, Pittet MJ, Swirski FK, Koteliansky V, Langer R, Weissleder R, Anderson DG, Nahrendorf $M$. Therapeutic sirna silencing in inflammatory monocytes in mice. Nat Biotechnol. 2011; 29: 10051010

38) Nagaoka K, Matoba T, Mao Y, Nakano Y, Ikeda G, Egusa S, Tokutome M, Nagahama R, Nakano K, Sunagawa K, Egashira K. A new therapeutic modality for acute myocardial infarction: Nanoparticle-mediated delivery of pitavastatin induces cardioprotection from ischemia-reperfusion injury via activation of pi3k/akt pathway and anti-inflammation in a rat model. PLoS One. 2015; 10: e0132451

39) Nagahama R, Matoba T, Nakano K, Kim-Mitsuyama $S$, Sunagawa K, Egashira K. Nanoparticle-mediated delivery of pioglitazone enhances therapeutic neovascularization in a murine model of hindlimb ischemia. Arterioscler Thromb Vasc Biol. 2012; 32: 2427-2434

40) Nakano K, Egashira K, Masuda S, Funakoshi K, Zhao G, Kimura S, Matoba T, Sueishi K, Endo Y, Kawashima Y, Hara K, Tsujimoto H, Tominaga R, Sunagawa K. Formulation of nanoparticle-eluting stents by a cationic electrodeposition coating technology: Efficient nano-drug delivery via bioabsorbable polymeric nanoparticle-eluting stents in porcine coronary arteries. JACC Cardiovasc Interv. 2009; 2: 277-283

41) Kawashima Y, Yamamoto H, Takeuchi H, Hino T, Niwa T. Properties of a peptide containing dl-lactide/glycolide copolymer nanospheres prepared by novel emulsion solvent diffusion methods. Eur J Pharm Biopharm. 1998; 
45: $41-48$

42) Longmire M, Choyke PL, Kobayashi H. Clearance properties of nano-sized particles and molecules as imaging agents: Considerations and caveats. Nanomedicine (Lond). 2008; 3: 703-717

43) Chrastina A, Massey KA, Schnitzer JE. Overcoming in vivo barriers to targeted nanodelivery. Wiley Interdiscip Rev Nanomed Nanobiotechnol. 2011; 3: 421-437

44) Lu JM, Wang X, Marin-Muller C, Wang H, Lin PH, Yao $\mathrm{Q}$, Chen C. Current advances in research and clinical applications of plga-based nanotechnology. Expert Rev Mol Diagn. 2009; 9: 325-341

45) Katsuki S, Matoba T, Nakashiro S, Sato K, Koga J, Nakano K, Nakano Y, Egusa S, Sunagawa K, Egashira K. Nanoparticle-mediated delivery of pitavastatin inhibits atherosclerotic plaque destabilization/rupture in mice by regulating the recruitment of inflammatory monocytes. Circulation. 2014; 129: 896-906

46) Tsukie N, Nakano K, Matoba T, Masuda S, Iwata E, Miyagawa M, Zhao G, Meng W, Kishimoto J, Sunagawa K, Egashira K. Pitavastatin-incorporated nanoparticleeluting stents attenuate in-stent stenosis without delayed endothelial healing effects in a porcine coronary artery model. J Atheroscler Thromb. 2013; 20: 32-45

47) Masuda S, Nakano K, Funakoshi K, Zhao G, Meng W, Kimura S, Matoba T, Miyagawa M, Iwata E, Sunagawa K, Egashira K. Imatinib mesylate-incorporated nanoparticleeluting stent attenuates in-stent neointimal formation in porcine coronary arteries. J Atheroscler Thromb. 2011; 18: $1043-1053$

48) Nakashiro S, Matoba T, Umezu R, Koga JI, Tokutome M, Katsuki S, Nakano K, Sunagawa K, Egashira K. Pioglitazone-incorporated nanoparticles prevent plaque destabilization and rupture by regulating monocyte/macrophage differentiation in apoe-/- mice. Arterioscler Thromb Vasc Biol. 2016: xx: $\mathrm{x}-\mathrm{x}$

49) Kubo M, Egashira K, Inoue T, Koga J, Oda S, Chen L, Nakano K, Matoba T, Kawashima Y, Hara K, Tsujimoto H, Sueishi K, Tominaga R, Sunagawa K. Therapeutic neovascularization by nanotechnology-mediated cellselective delivery of pitavastatin into the vascular endothelium. Arterioscler Thromb Vasc Biol. 2009; 29: 796-801

50) Oda S, Nagahama R, Nakano K, Matoba T, Kubo M, Sunagawa K, Tominaga R, Egashira K. Nanoparticlemediated endothelial cell-selective delivery of pitavastatin induces functional collateral arteries (therapeutic arteriogenesis) in a rabbit model of chronic hind limb ischemia. J Vasc Surg. 2010; 52: 412-420

51) Kimura S, Egashira K, Nakano K, Iwata E, Miyagawa M, Tsujimoto H, Hara K, Kawashima Y, Tominaga R, Sunagawa K. Local delivery of imatinib mesylate (sti571)incorporated nanoparticle ex vivo suppresses vein graft neointima formation. Circulation. 2008; 118: S65-70

52) Frantz $S$, Nahrendorf $M$. Cardiac macrophages and their role in ischaemic heart disease. Cardiovasc Res. 2014; 102: $240-248$

53) Mulder WJ, Strijkers GJ, Briley-Saboe KC, Frias JC, Aguinaldo JG, Vucic E, Amirbekian V, Tang C, Chin PT, Nicolay K, Fayad ZA. Molecular imaging of macrophages in atherosclerotic plaques using bimodal peg-micelles. Magn Reson Med. 2007; 58: 1164-1170

54) Starmans LW, Burdinski D, Haex NP, Moonen RP, Strijkers GJ, Nicolay K, Grull H. Iron oxide nanoparticlemicelles (ion-micelles) for sensitive (molecular) magnetic particle imaging and magnetic resonance imaging. PLoS One. 2013; 8: e57335

55) Imai Y, Kaneko E, Asano T, Kumagai M, Ai M, Kawakami A, Kataoka K, Shimokado K. A novel contrast medium detects increased permeability of rat injured carotid arteries in magnetic resonance t 2 mapping imaging. J Atheroscler Thromb. 2007; 14: 65-71

56) Khan OF, Zaia EW, Jhunjhunwala $S$, Xue W, Cai W, Yun DS, Barnes CM, Dahlman JE, Dong Y, Pelet JM, Webber MJ, Tsosie JK, Jacks TE, Langer R, Anderson DG. Dendrimer-inspired nanomaterials for the in vivo delivery of sirna to lung vasculature. Nano Lett. 2015; 15: 30083016

57) Liu J, Gu C, Cabigas EB, Pendergrass KD, Brown ME, Luo Y, Davis ME. Functionalized dendrimer-based delivery of angiotensin type 1 receptor sirna for preserving cardiac function following infarction. Biomaterials. 2013; 34: 3729-3736

58) Pok S, Vitale F, Eichmann SL, Benavides OM, Pasquali M, Jacot JG. Biocompatible carbon nanotube-chitosan scaffold matching the electrical conductivity of the heart. ACS Nano. 2014; 8: 9822-9832

59) Cao Y, Roursgaard M, Jacobsen NR, Moller P, Loft S. Monocyte adhesion induced by multi-walled carbon nanotubes and palmitic acid in endothelial cells and alveolar-endothelial co-cultures. Nanotoxicology. 2015: 1-10 